\title{
Hospital pharmacy workforce in Brazil
}

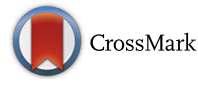

\author{
Thiago R. Santos ${ }^{1}$, Jonathan Penm ${ }^{2,3}$, André O. Baldoni ${ }^{1}$, Lorena Rocha Ayres ${ }^{4}$, Rebekah Moles ${ }^{2,3}$ \\ and Cristina Sanches ${ }^{1 *}$ (D)
}

\begin{abstract}
Background: This study aims to describe the distribution of the hospital pharmacy workforce in Brazil.

Methods: Data were acquired, during 2016, through the Brazilian National Database of Healthcare Facilities (CNES). The following variables were extracted: hospital name, registry number, telephone, e-mail, state, type of institution, subtype, management nature, ownership, presence of research/teaching activities, complexity level, number of hospital beds, presence of pharmacists, number of pharmacists, pharmacist specialization. All statistical analyses were performed by IBM SPSS v.19.

Results: The number of hospitals with a complete registry in the national database was 4790 . The majority were general hospitals (77.9\%), managed by municipalities (66.1\%), under public administration (44.0\%), had no research/ teaching activities (90.5\%), classified as medium complexity (71.6\%), and had no pharmacist in their team (50.6\%). Furthermore, almost $60.0 \%$ of hospitals did not comply with the minimum recommendations of having a pharmacist per 50 hospital beds. The Southeast region had the highest prevalence of pharmacists, with 64.4\% of hospitals having a pharmaceutical professional. This may have occurred as this region had the highest population to hospital ratio. Non-profit hospitals were more likely to have pharmacists compared to those under public administration and private hospitals.
\end{abstract}

Conclusion: This study mapped the hospital pharmacy workforce in Brazil, showing a higher prevalence of hospital pharmacists in the Southeast region, and in non-profit specialized hospitals.

Keywords: Health services, Hospital pharmaceutical service, Pharmacists, Brazil

\section{Background}

The third Global Patient Safety Challenge is Medication Safety. This highlights the importance of trying to diminish unsafe medication practices and medication errors. The impact of these errors is particularly evident in the hospital setting. Key policy documents highlight the skills of the pharmacists to conduct medication reconciliation and to reduce polypharmacy [1]. In 2013, the World Health Organization (WHO) estimated a global workforce shortage of 7.2 million healthcare professionals [2]. As such, WHO recommends that each country develop a national health workforce strategy that prepares the future workforce, enhances current worker performances, and manages attrition [3]. This strategy should help prepare the workforce response to

\footnotetext{
* Correspondence: csanches@ufsj.edu.br

${ }^{1}$ Federal University of Sao Joao del Rei, Campus Centro-Oeste Dona Lindu, Av. Sebastião Gonçalves Coelho, 400 - Chanadour, Divinópolis, MG CEP 35.501-296, Brazil

Full list of author information is available at the end of the article
}

the aging population and growing burden of chronic disease $[4,5]$.

Pharmacists' expertise is particularly important in the hospital setting where patients are acutely unwell and often started on invasive, high-risk medications that can interact with other pre-existing medications. As such, the International Pharmaceutical Federation released the Basel Statements for the future of hospital pharmacy that state: "Health authorities should ensure that each hospital is serviced by a pharmacy that is supervised by pharmacists who have completed advanced training in hospital pharmacy" [6, 7].

Furthermore, the Basel Statements also target human resources, training and development issues and state:

Hospitals should maintain human resource information systems that contain basic data for planning, training, appraising, and supporting the 
workforce. Data should be collated at a national level to improve workforce planning.

The Basel Statements further highlight the important role of hospital pharmacists to optimize patient outcomes through responsible use of medicines. This includes not only timely access to safe and effective medicines, but that medicines are only used when necessary and that the choice of medicine is appropriate based on clinical evidence and safety to prevent medication errors [8-11]. To ensure all patients receive appropriate medications, some countries like the United States of America (USA) have also utilized pharmacy support staff, such as pharmacy technicians, to take on technical and basic clinical responsibilities while their pharmacists target advanced care patients [12].

Brazil has also acknowledged the importance of hospital pharmacists with laws stating they must be present in all hospitals [13, 32]. In addition, the Minimum Standards for Hospital Pharmacy and Healthcare Services recommend at least one pharmacist for every 50 hospital beds for basic dispensing services [14]. Despite these recommendations and growing evidence that hospital pharmacy services improve patients' clinical outcomes $[15,16]$, low compliance with these legal requirements and standards have been observed [17]. Brazil currently has a higher density of pharmacists (9.1 per 10,000 population) than the global average (6 per 10,000 population) with growing capacity over the past years [4, 18]. Additionally, expressive gains were obtained concerning pharmaceutical care [19-21]. However, to the best of our knowledge, current studies have not evaluated the distribution of the hospital pharmacy workforce in Brazil [4, 18]. This study aimed to describe the pharmacy workforce distribution in hospital settings in Brazil.

\section{Methods}

This was a cross-sectional study.

Data were acquired through the National Database of Healthcare Facilities (CNES), via website (http://cnes2.datasus.gov.br). The following variables hospital name, registry number, telephone, e-mail, address, state, type and subtype of institution, management nature, ownership, presence of research/teaching activities, hospital complexity level, number of hospital beds, presence of pharmacists, number of pharmacists, and pharmacist specialization were extracted, aided by an online platform provided by Google Forms. Data were collected from a single government-run database from February of 2016 to September of 2016.

States were coded and clustered into regions, as defined by IBGE - North, Northeast, Central-West, Southeast and
South. Management was divided into city, state or both. Hospitals with both city and state management were labeled as "joint" [22].

According to Brazilian classification, medium complexity hospitals are those with availability of specialized professionals and technological resources aimed at resolving major health issues of the local population, and high complexity hospitals are those with high technology resources and costs, aiming to provide qualified services to the population, integrating those services with the other levels of health assistance, as primary care and medium complexity [23].

Legal ownership was also clustered into three categories as defined by IBGE, which are (1) Public; (2) Private, and (3) Non-profit organization, as shown in Table 1.

Table 1 Legal ownership clustering, as defined by IBGE [43]

\begin{tabular}{|c|c|}
\hline Classification & Types \\
\hline \multirow[t]{12}{*}{ Public } & City \\
\hline & City foundation \\
\hline & Public agency of municipality executive power \\
\hline & Public agency of federal executive power \\
\hline & Public agency of state or federal district executive power \\
\hline & State or federal district \\
\hline & State or federal district autarchy \\
\hline & State or federal district foundation \\
\hline & Public foundation of municipality private law \\
\hline & City autarchy \\
\hline & Federal autarchy \\
\hline & Public association \\
\hline \multirow[t]{12}{*}{ Private } & Limited company \\
\hline & Limited liability company (of simple nature) \\
\hline & Limited partnership \\
\hline & Closed corporation \\
\hline & Pure simple society \\
\hline & Cooperative company \\
\hline & Businessman (individual) \\
\hline & Simple society in collective name \\
\hline & Limited liability company (of business nature) \\
\hline & Open corporation \\
\hline & Joint capital business \\
\hline & Public corporation \\
\hline \multirow[t]{6}{*}{ Non-profit } & Private association \\
\hline & Private foundation \\
\hline & Autonomous social service \\
\hline & Syndical entity \\
\hline & Social organization \\
\hline & Religious organization \\
\hline
\end{tabular}


Medical laboratory scientists were not counted as hospital pharmacists despite some crossover in roles in the country. Additionally, pharmacy technicians are not registered at CNES; therefore, data regarding these support staff were not collected.

Maps were produced by Google Maps online system, using hospitals' names and addresses. Absence of pharmacists was considered when no registry of pharmacists working for hospitals was found.

Statistical analyses were performed using IBM SPSS 19.0. The presence or absence of hospital pharmacists was compared with the following variables: type of institution, presence of research/teaching activities, complexity, region, subtype, management nature, and ownership. The continuous variable, number of hospitals beds, was recodified to a nominal variable according the median value of 40 hospital beds. Data normality was evaluated by Kolmogorov-Smirnorv test; medians of number of hospital beds were compared by Mann-Whitney $U$ test. Nominal and categorical data were compared by binary logistic regression (odds ratio and 95\%CI). Variables with $p<0.2$ from the univariate analysis and those with plausibility to be inserted according to the literature were included in the multivariate model. The variable "subtypes of specialized hospital" was not included, as it is a subpart of "type of institution". The stepwise backward method was used in order to insert the variables, and only the significant variables with $p<0.5$ remained. The explanatory variables used in the multivariate model were as follows: type of institution, presence of research/ teaching activities, complexity, region, management nature, and ownership. Data were considered statistically significant when $p<0.05$.

States' Gross Domestic Product (GDP) obtained at IBGE [22] was correlated to the total number of pharmaceutical professionals in each of the 27 Brazilian States, by Spearman correlation.

\section{Results}

From a total of 6385 registries of hospitals in the $\mathrm{Na}$ tional Database of Healthcare Facilities, 908 (13.8\%) were duplicates and $687(10.8 \%)$ were missing all data. Hence, these were excluded. The final sample size was 4790 (75.0\%) (Fig. 1).

The distribution of hospitals among the Brazilian regions is presented in Table 2. The North region had the least number of hospitals and the Northeast region had the highest number of hospitals. Regarding the number of hospital beds per 1000 people, the lowest and highest ratios were the North and South regions respectively.

Hospital characteristics are described in Table 3.

Regarding the presence of pharmacists, more than half of the hospitals lacked a hospital pharmacist in their healthcare team, being 2426 (50.6\%) institutions

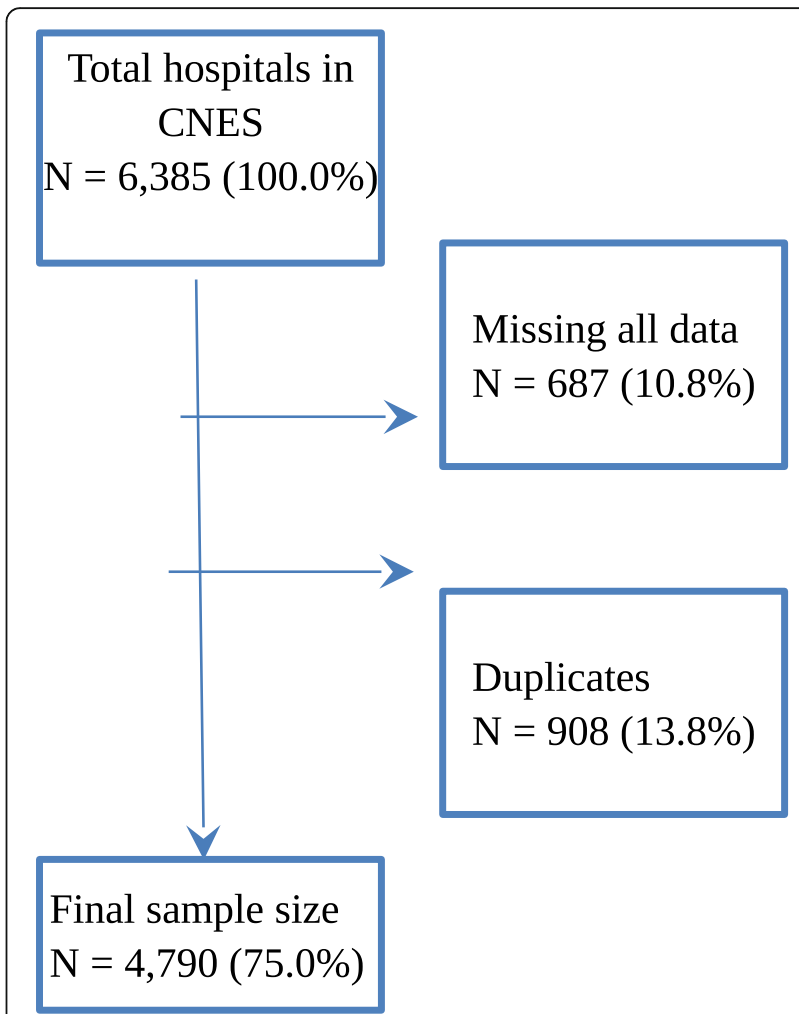

Fig. 1 Selection flowchart of hospitals for data analysis

without a single pharmacist versus 2364 (49.4\%) with one or more pharmacists (Table 4). There was a significant association between number of hospital beds and the presence of pharmacists. Hospitals with a median of 30 (15-50, interquartile range) hospital beds were those with the absence of the professional, while a median of $58(32-116)$ beds had at least one pharmacist $(p<0.0001)$.

Figure 2 presents the geographic distribution of pharmacists. From 2438 hospitals with a pharmacist, 707 (29.0\%) did not meet the minimum national requirement of one pharmacist per 50 hospital beds [18]. Ninety (3.7\%) hospitals did not contain enough information to calculate a pharmacist to hospital beds ratio.

A positive correlation was obtained between GDP and the total number of pharmaceutical professionals in each of the 27 Brazilian states $\left(r^{2} 0.958 ; p<0.0001\right)$.

\section{Discussion}

Worldwide, the role of hospital pharmacists in promoting responsible use of medicines has made them an invaluable resource $[8,9]$. However, according to the main findings of our study, pharmacists were present in less than half of the Brazilian hospitals and were unevenly distributed across the country. These findings reinforce the urgent need to implement policies and procedures to track and monitor 
Table 2 Hospital distribution among Brazilian geographic regions compared with population distribution and hospital beds [44]

\begin{tabular}{|c|c|c|c|c|}
\hline Region & $\begin{array}{l}\text { Frequency } \\
n(\%)\end{array}$ & $\begin{array}{l}\text { Hospital beds } \\
n(\%)\end{array}$ & Region population [44] & $\begin{array}{l}\text { Hospital beds/10 } 000 \\
\text { population }\end{array}$ \\
\hline Central-West & $604(12.6)$ & $26173(8.4)$ & 15219608 & 17.2 \\
\hline North & $423(8.8)$ & $23315(7.5)$ & 17231027 & 13.5 \\
\hline Northeast & $1539(32.1)$ & $83404(26.8)$ & 56186190 & 14.8 \\
\hline South & $746(15.6)$ & $51132(16.4)$ & 29016144 & 17.6 \\
\hline Southeast & $1478(30.9)$ & $127091(40.8)$ & 85115623 & 14.9 \\
\hline Total & $4790(100)$ & $311115(100)$ & 202768562 & 15.3 \\
\hline
\end{tabular}

Table 3 Description of Brazilian hospitals considering type, subtypes, management nature, ownership, teaching, and complexity

\begin{tabular}{|c|c|c|}
\hline & $\begin{array}{l}\text { Absolute frequency } \\
(n)\end{array}$ & Relative frequency (\%) \\
\hline \multicolumn{3}{|l|}{ Type of institution } \\
\hline General hospital & 3732 & 77.9 \\
\hline Specialized hospital & 1058 & 22.1 \\
\hline Total & 4790 & 100.0 \\
\hline \multicolumn{3}{|c|}{ Subtypes of specialized hospitals } \\
\hline Cardiology & 64 & 6.1 \\
\hline Maternity & 154 & 14.6 \\
\hline Oncology & 56 & 5.3 \\
\hline Orthopaedics & 47 & 4.4 \\
\hline Paediatrics & 114 & 10.8 \\
\hline Psychiatry & 230 & 21.7 \\
\hline NA & 393 & 37.1 \\
\hline Total & 1058 & 100.0 \\
\hline \multicolumn{3}{|l|}{ Management nature } \\
\hline Municipality & 3168 & 66.1 \\
\hline Joint & 906 & 18.9 \\
\hline State & 716 & 14.9 \\
\hline Total & 4790 & 100.0 \\
\hline \multicolumn{3}{|l|}{ Legal ownership } \\
\hline Private & 1511 & 31.5 \\
\hline Non-profit & 1170 & 24.4 \\
\hline Public & 2109 & 44.0 \\
\hline Total & 4790 & 100.0 \\
\hline \multicolumn{3}{|c|}{ Presence of teaching/research activity } \\
\hline Yes & 457 & 9.5 \\
\hline No & 4333 & 90.5 \\
\hline Total & 4790 & 100.0 \\
\hline \multicolumn{3}{|l|}{ Complexity level } \\
\hline High complexity & 1359 & 28.4 \\
\hline Medium complexity & 3428 & 71.6 \\
\hline NA & 3 & 0.9 \\
\hline Total & 4790 & 100.0 \\
\hline
\end{tabular}

$N A$ information not available the presence of pharmacists in hospitals, practicing both clinically and administratively.

Even though the presence of pharmacists is assured by law in Brazil [13, 32], more than half (50.9\%) of the hospitals lacked a pharmaceutical professional on their team. The Minimum Standards for Hospital Pharmacy and Healthcare Services [14] recommend at least one pharmacist per 50 hospital beds. Almost $60 \%$ of the hospitals did not comply with this recommendation, working with critically low human resources. Far beyond the legal implications [22], the presence of hospital pharmacists is vital in clinical settings, avoiding clinical errors and improving quality of care [24-28]. Furthermore, the Brazilian Pharmacy Council recognizes six core activities of hospital pharmacy, including the following: 1 . Management; 2. Infrastructure development; 3. Preparation, distribution, dispensing and control of healthcare products; 4. Optimization of drug therapy; 5 . Provision of information about drugs and healthcare products; and 6. Providing education and research [29]. The absence of this particular professional therefore impairs the quality of the health care services provided by these medical facilities.

Additionally, the Basel Statements for the future of hospital pharmacy, produced under the auspice of FIP also states six core areas of hospital pharmacist activities that include pharmacists overseeing procurement; influences on prescribing; preparation and delivery of medicines; administration; monitoring of medicine use; and Human Resources and training [4-7]. These global statements therefore align with those of the Brazilian Pharmacy Council and highlight the positive role that pharmacists can make to improve the health care service and patient outcomes.

In this study, the presence of pharmacists was higher in hospitals with Research/Teaching Activities. Even so, $18.6 \%$ of them still did not have any pharmacists. As "teaching and research" are a component of a pharmacist's profession [14], the lack of these professionals in some institutions disappointingly shows that they may not be considered as valued in all of these hospitals.

Encouragingly, from 1359 hospitals labeled as "High Complexity", $67.4 \%$ had pharmacists, and these data stood 


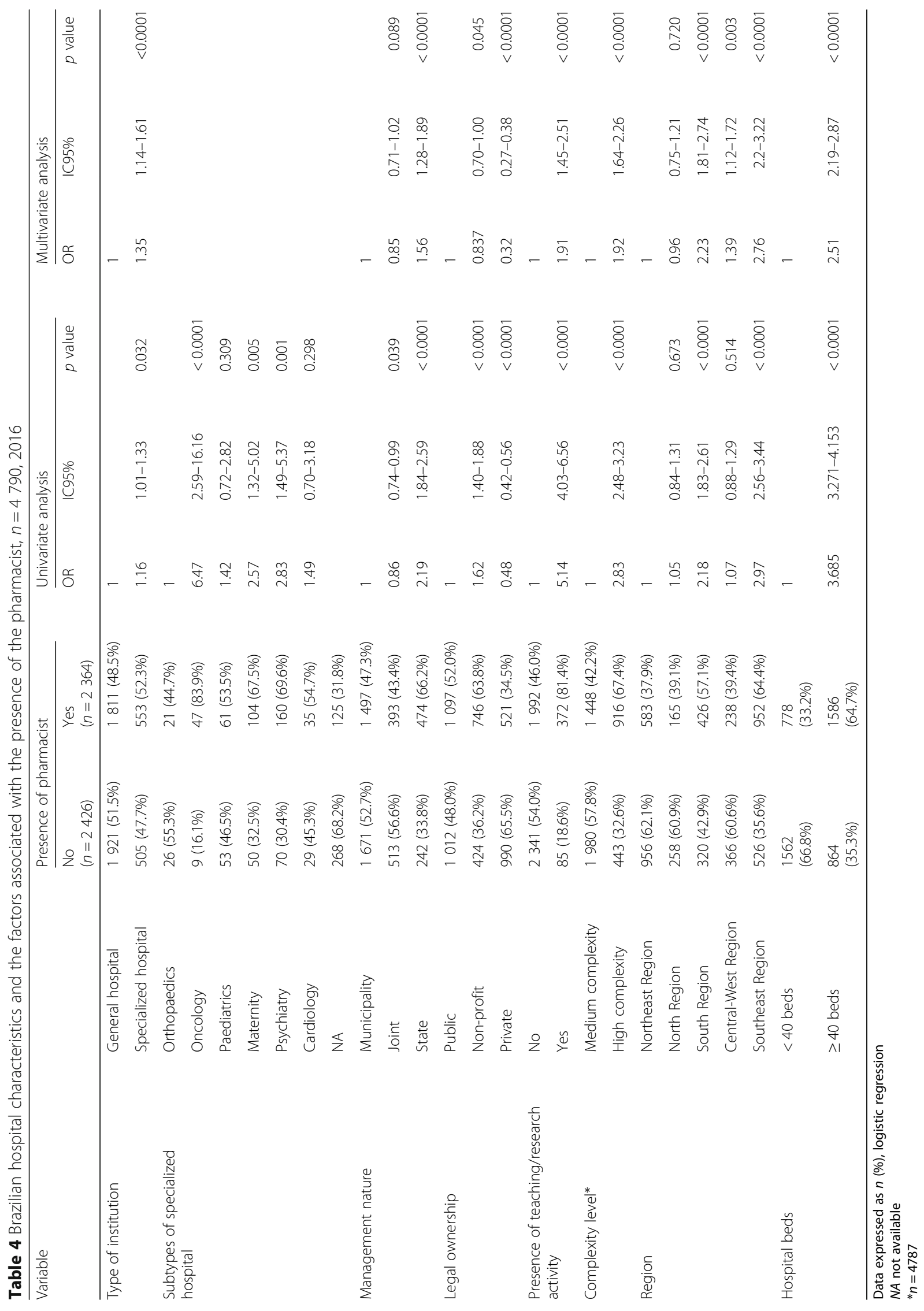




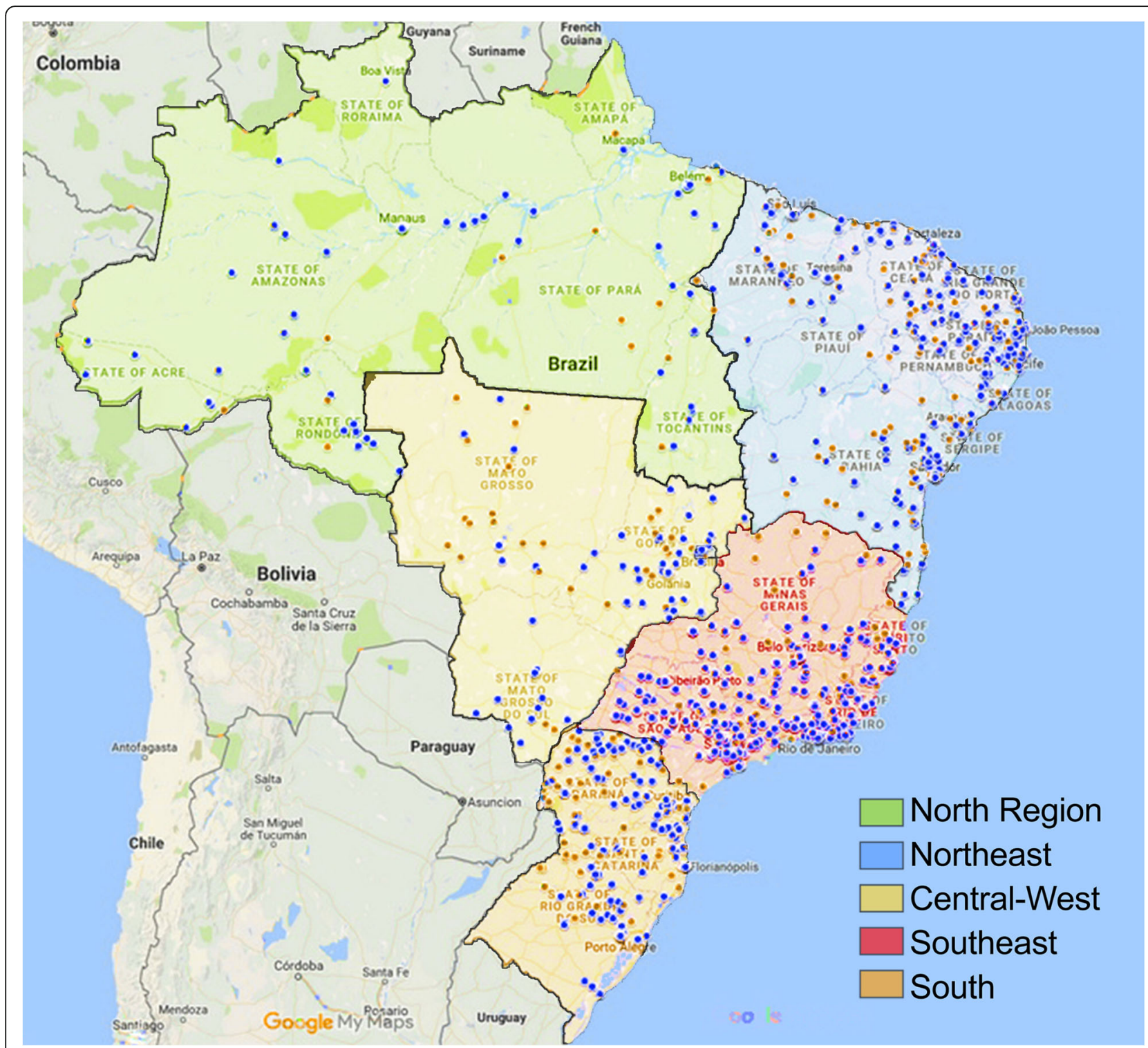

Fig. 2 Geographic localization of Brazilian hospitals with pharmacists (blue circles) and without pharmacists (orange circles), according CNES $\left(\right.$ Google Maps $\left.^{\circledR}\right)$

out when compared to "Medium Complexity" hospitals with only $42.2 \%$ having pharmacists. Similarly, there was a predominance of pharmacists in specialized hospitals compared to general hospitals. Yet, some specialized hospitals still lacked access to pharmaceutical care services which may impact on patient-specific successful clinical outcomes [30,31].

Despite the importance of pharmacists in hospital settings, legally in Brazil, their presence should be guaranteed in oncology and psychiatric hospitals [32, 33]. In our study, more than $80 \%$ of the hospitals labeled as "oncology specialized" had pharmacists; however, this may be due to their activities in compounding pharmacy, especially regarding antineoplastic medicines [32], and it is unclear if these pharmacists have further roles that cover more aspects of pharmacy services as outlined in the Basel Statements [7]. In psychiatric hospitals, the Brazilian hospital pharmacy landscape in this study was shown to be inappropriate, lacking professionals properly trained to solve medication-related issues, despite the legal requirements and strict control by sanitary and civil authorities upon these substances [33, 34]. The absence of the health care professional should be highlighted and inspected by sanitary authorities.

Regarding the management of hospitals, most were managed by municipalities. The minority, managed by states, showed a higher prevalence of pharmacists. Apparently, state management agencies present more severe criteria 
and/or control to organize health care professionals, but more studies are necessary to evaluate the influence of these variables upon pharmacy practice.

As hospitals were clustered by ownership, those labeled as "business entities" had the lowest pharmacist to bed ratios. In contrast, non-profit organizations showed a prevalence of $63.8 \%$ of pharmacists. Also, more than half $(52.02 \%)$ of the hospitals under public administration did not have pharmacists. Thus, many public institutions are currently not legally compliant. On the other hand, non-profit organizations tended to spend more money on human resources, perhaps as they are not aiming for profit. Non-profit organizations have recognizable contributions to improve public health all over the world [35-37], and in the perspective of pharmacist workforce in Brazil, it appears to be an advantage, perhaps indicating that they see the benefit of integrating pharmacists into their multidisciplinary teams.

Additionally, the distribution of pharmacists was uneven across the Brazilian regions. In North, Northeast, and Central-West regions, less than half of hospitals had pharmacists, compared to data from South and Southeast regions. The region with the highest presence of pharmacists and the highest population to hospitals ratio was the Southeast region. In contrast, the Northeast region presented the highest absolute count of hospitals with lowest prevalence of pharmacists. These regional differences are far beyond pharmacist presence. Historically, Brazilian regions present extreme inequalities (demographic, economic, social, cultural, and sanitary) even for access to the health system [38, 39].

In the present study, a positive correlation was obtained between GDP and the total number of hospital pharmacists in each Brazilian state. These results are in accordance with Bates et al. They found a positive correlation between economic development and expenditure on health and pharmacist availability [18]. The south and southeast regions of Brazil make up 76.1\% of the Brazilian Gross National Product [22]. It therefore could be plausible that pharmacists are not seen as an essential resource and only considered as an investment when additional resources are available. This contrast between need for services and access to it, in a mediumto long-term perspective, could result in a collapse in the country's health system, as the population ages [22], and they demand more intensive healthcare services, including pharmaceutical care [40].

While in developed countries such as the USA, pharmacy technicians are taking on administrative and clinical responsibilities to support pharmacists, this is not yet the case in Brazil $[12,15,16]$. Brazilian studies conducted by Magarinos-Torres et al. and Freitas et al. described factors negatively influencing pharmacists' clinical responsibilities: the hospital manager is not interested in clinical activities or does not recognize the pharmacist as a clinical professional; insufficient clinical training in undergraduate studies; difficulty interacting with other professional categories; pharmacists do not recognize themselves as healthcare professionals and do not understand they can perform clinical functions; no structural contribution to develop clinical activities; administrative, logistic and bureaucratic time-consuming tasks, not leaving time for clinical activities [17, 41].

This study has provided an important snapshot of the pharmacist workforce across Brazilian hospitals. The main limitation of this study is the use of a governmentmanaged database, in a cross-sectional study; thus, some data may be out of date. The mandatory registration of all Brazilian healthcare facilities in CNES was established by law and data are validated by unannounced visits [42]. Moreover, the database was unable to provide information in which field the pharmacist was practicing (clinical or administrative functions).

\section{Conclusion}

Pharmacists are distributed unevenly in Brazil. The pharmaceutical workforce is slightly concentrated in specialized hospitals, with non-profit organization ownership in the Southeast region. However, it was clear there was a lack of pharmaceutical registration in hospital settings, especially in general hospitals located in Northeast, North, and Central-West Brazilian regions. Law enforcement should be performed to ensure all hospitals have, at least, one pharmacist per 50 beds, assuring quality in the healthcare process and more success in clinical outcomes. Finally, further exploratory studies are required to assess the presence of the pharmacist and their work conditions on a local scale, focussing on their clinical and administrative roles and reinforcing their need in hospitals.

\section{Abbreviations \\ CNES: National Database of Healthcare Facilities; FIP: International \\ Pharmaceutical Federation; GDP: Gross Domestic Product; IBGE: Brazilian Institute of Geography and Statistics; WHO: World Health Organization}

\section{Acknowledgements \\ Authors are grateful to FIP - Hospital Pharmacy Section, for support. \\ Funding \\ This work was supported by The International Pharmaceutical Federation (FIP), agreement number 089/2016. \\ Availability of data and materials \\ The datasets analysed during the current study are available in National Database of Healthcare Facilities (CNES). These datasets was derived from the following public domain resources (http://cnes2.datasus.gov.br/).}

Authors' contributions

TRS and CS made substantial contributions to acquisition and analysis of data. JP, AOB, LRA, RM, and CS contributed in conception, design, and 
interpretation of data. All authors were involved in drafting the manuscript and revising it critically and approved the final version.

\section{Ethics approval and consent to participate}

Not applicable.

\section{Consent for publication}

Not applicable.

\section{Competing interests}

TRS, JP, AOB, LRA, RM, and CS have no competing interests to declare.

\section{Publisher's Note}

Springer Nature remains neutral with regard to jurisdictional claims in published maps and institutional affiliations.

\section{Author details}

${ }^{1}$ Federal University of Sao Joao del Rei, Campus Centro-Oeste Dona Lindu, Av. Sebastião Gonçalves Coelho, 400 - Chanadour, Divinópolis, MG CEP 35.501-296, Brazil. ${ }^{2}$ Hospital Pharmacy Section, International Pharmaceutical Federation, The Hague, The Netherlands. ${ }^{3}$ Faculty of Pharmacy, University of Sydney, Camperdown, NSW, Australia. ${ }^{4}$ Department of Pharmaceutical Sciences, Federal University of Espírito Santo, Vitória, Brazil.

Received: 27 June 2017 Accepted: 15 December 2017

\section{Published online: 04 January 2018}

\section{References}

1. Medication Without Harm - Global Patient Safety Challenge on Medication Safety. Geneva: World Health Organization; 2017. Licence: CC BY-NC-SA 3.0 IGO.

2. Campbell J, Dussault G, Buchan J, Pozo-Martin F, Guerra Arias M, Leone C, Siyam A, Cometto G. A universal truth: no health without a workforce. Forum Report, Third Global Forum on Human Resources for Health, Recife, Brazil. Geneva: Global Health Workforce Alliance and World Health Organization; 2013.

3. Chen L, Evans D, Evans T, Sadana R, Stilwell B, Travis P, et. al. The world health report 2006: working together for health. Geneva: World Health Organization; 2016.

4. International Pharmaceutical Federation (FIP). Global Pharmacy Workforce Intelligence: Trends Report 2015. The Hague: International Pharmaceutical Federation; 2015.

5. International Pharmaceutical Federation (FIP) 2012 FIP Global Pharmacy Workforce Report. The Hague: International Pharmaceutical Federation; 2012.

6. The Basel Statements on the future of hospital pharmacy. Am J Health Syst Pharm. 2009;66(5 Suppl 3):S61-6. https://doi.org/10.2146/ajhp080666.

7. Moles RJ, Vermeulen L, Penm J, Ivey M. The Basel statements: updated and relevant to all. Can J Hosp Pharm. 2016;69(2):101-2.

8. Perez A, Doloresco F, Hoffman JM. ACCP: economic evaluations of clinical pharmacy services: 2001-2005. Pharmacotherapy. 2008;28:285e-323e.

9. Wickens HJ, Farrell S, Ashiru-Oredope DAl, et al. The increasing role of pharmacists in antimicrobial stewardship in English hospitals. J Antimicrob Chemother. 2013;68:2675-81. https://doi.org/10.1093/jac/dkt241.

10. Dabaghzadeh F, Rashidian A, Torkamandi H, Alahyari S, et al. Medication errors in an emergency department in a large teaching hospital in Tehran. Iranian J Pharm Research. 2013;12(4):937-42.

11. Broom A, Broom J, Kirby E, Plage S, Adams J. What role do pharmacists play in mediating antibiotic use in hospitals? A qualitative study. BMJ Open. 2015;5:e008326. https://doi.org/10.1136/bmjopen-2015-008326.

12. Desselle SP, Holmes ER. Results of the 2015 National Certified Pharmacy Technician Workforce Survey. Am J Health-Syst Pharm. 2017;74:e295-306.

13. Brazilian Institute of Geography and Statistics. Population Estimates of Brazilian Cities as of Reference in July 1st, 2011. http://www.ibge.gov.br/home/estatistica/ populacao/estimativa2011/POP2011_DOU.pdf. Accessed 16 Nov 2016.

14. Brazilian Society of Hospital Pharmacy. Padrões Mínimos para Farmácia Hospitalar. Goiânia; 2007. p. 20. http://www.sbrafh.org.br/site/public/temp/ 4f7baaa6b63d5.pdf.

15. Reis WCT, Scopel CT, Correr CJ, Andrzejevski VMS. Analysis of clinical pharmacist interventions in a tertiary teaching hospital in Brazil. Einstein (São Paulo). 2013;11(2):190-6.
16. Miranda TMN, Petriccione S, Ferracini FT, Borges Filho WM. Intervenções realizadas pelo farmacêutico clínico na unidade de primeiro atendimento. Einstein (São Paulo). 2012;10(1):74-8.

17. Magarinos-Torres R, Osorio-de-Castro CGS, Pepe VLE. Atividades da farmácia hospitalar brasileira para com pacientes hospitalizados: uma revisão da literatura. Ciênc saúde coletiva. 2007;12(4):973-84.

18. Bates I, John C, Bruno A, Fu P, Aliabadi S. An analysis of the global pharmacy workforce capacity. Hum Resour Health. 2016;14:61.

19. Federal Pharmaceutical Council. Resolution 585, August 29th 2013. Available at: http://www.cff.org.br/userfiles/file/resolucoes/585.pdf.

20. Borges APS, Guidoni CM, Freitas O, Pereira LRL. Economic evaluation of outpatients with type 2 diabetes mellitus assisted by a pharmaceutical care service. Arq Bras Endocrinol Metab. 2011;55(9):686-91.

21. Obreli-Neto PR, Guidoni CM, Baldoni AO, Pilger D, Cruciol-Souza JM, GaetiFranco WP, Cuman RK. Effect of a 36-month pharmaceutical care program on pharmacotherapy adherence in elderly diabetic and hypertensive patients. Int J Clin Pharm. 2011;33(Issue 4):642-9.

22. Brazilian Institute of Statistics and Geography. Projection of population of Brazil and states. http://www.ibge.gov.br/apps/populacao/projecao/. Accessed 16 Nov 2016

23. Brasil. Conselho Nacional de Secretários de Saúde. Assistência de Média e Alta Complexidade no SUS / Conselho Nacional de Secretários de Saúde. Brasília: CONASS; 2007. p. 248.

24. Wimmer BC, Cross AJ, Jokanovic N, Wiese MD, et al. Clinical outcomes associated with medication regimen complexity in older people: a systematic review. J Am Geriatr Soc. 2016. https://doi.org/10.1111/jgs.14682. Epub ahead of print.

25. Laliberte MC, Perreault S, Damestoy N, Lalonde L. Ideal and actual involvement of community pharmacists in health promotion and prevention: a cross-sectional study in Quebec, Canada. BMC Public Health. 2012;12:192.

26. International Pharmaceutical Federation. Revised FIP Basel statements on the future of hospital pharmacy. Bangkok; 2014. http://fip.org/files/fip/FIP BASEL_STATEMENTS_ON_THE_FUTURE_OF_HOSPITAL_PHARMACY_2015. pdf. Accessed 17 Nov 2016.

27. Viguier F, Roessle C, Zerhouni L, Rouleau A, et al. Clinical pharmacist influence at hospital to prevent overdosed prescription of acetaminophen. Ann Pharm Fr 2016; 74(6):482-488.

28. Davis EM, Packard KA, Jackevicius CA. The pharmacist role in predicting and improving medication adherence in heart failure patients. J Manag Care Spec Pharm. 2014;20(7):741-55.

29. Brazil. Conselho Regional de Farmácia do Estado de São Paulo. Farmácia Hospitalar./Conselho Regional de Farmácia do Estado de São Paulo. - São Paulo: Conselho Regional de Farmácia do Estado de São Paulo; 2012. p. 59; 22,5 cm. -ISBN 978-85-63931-27-6.

30. Moullim SM, Eutrópio FJ, Souza JO, Busato FO, Olivieri DN, Tadokoro CE. The role of clinical pharmacists in treatment adherence: fast impact in suppression of chronic myeloid leukemia development and symptoms. Support Care Cancer. 2016. Epub ahead of print.

31. Forouguinia F, Tazarehie SR, Petramfar P. Detecting and managing drugrelated problems in the neurology ward of a tertiary care teaching hospital in Iran: a clinical pharmacist's intervention. J Res Pharm Pract. 2016;5(4):285-9.

32. Brazil. Decree number 85.878 , from April 7th, 1981. http://www.planalto.gov. br/ccivil_03/decreto/Antigos/D85878.htm. Accessed 1 Feb 2017.

33. Brazil. Resolution 344 of May 12th, 1998. National Agency of Health Surveillance. Available online at http://www.anvisa.gov.br/hotsite/ talidomida/legis/Portaria_344_98.pdf. Accessed 10 Feb 2017.

34. Wolf C, Pauly A, Mayr A, Grömer T, et al. Pharmacist-led medication reviews to identify and collaboratively resolve drug-related problems in psychiatry—a controlled, clinical trial. PLoS ONE. 2015;10(11):e0142011. https://doi.org/10.1371/journal.pone.0142011.

35. Zhang, et al. Effectiveness and impact of the cross- border healthcare model as implemented by non-governmental organizations: case study of the malaria control programs by health poverty action on the ChinaMyanmar border. Infect Dis Poverty. 2016;5:80. https://doi.org/10.1186/ s40249-016-0175-0.

36. Yagub AIA, Mtshali K. The role of non-governmental organizations in providing curative health services in North Darfur state, Sudan. Afri Health Sci. 2015;15(3):1049-55. https://doi.org/10.4314/ahs.v15i3.48.

37. Biermann O, Eckhardt M, Carlfjord S, Falk M, Forsberg BC. Collaboration between non-governmental organization and public services in health-a qualitative case study from rural Ecuador. Glob Health Act. 2016:9:32237. https://doi.org/10.3402/gha.v9.32237 
38. Andrade, Mônica Viegas et al. Desigualdade socioeconômica no acesso aos serviços de saúde no Brasil: um estudo comparativo entre as regiões brasileiras em 1998 e 2008. Econ Apl. [online]. 2013;17:4.

39. Buss PM, Labra ME, orgs. Sistemas de saúde: continuidades e mudanças [online]. Rio de Janeiro: Editora FIOCRUZ; 1995. p. 265. ISBN 85-271-0290-0. Available from SciELO Books.

40. Brazil. Law number 13.021, of August 8th of 2014, Presidency of the Republic, Brazil. http://www.planalto.gov.br/ccivil_03/_Ato2011-2014/2014/ Lei/L13021.htm. Accessed 17 Nov 2016.

41. Freitas GRM, Pinto RS, Luna-Leite MA, Catro MS, Heineck I. Main difficulties faced by pharmacists to exercise their clinical attributions in Brazil. Rev Bras Farm Hosp Serv Saúde. 2016;7(3):35-41.

42. Brazil. Portaria SAS/MS n 511. Ministry of Health. D.O.U. December 29, 2000 saude.gov.br/legisla/legisla/...SAS_P511_01control_av_g.doc.

43. Brazilian Institute of Statistics and Geography. Ownership Table for 2016 DOU no 82, from May 2, 2016. Accessed 16 Nov 2016. http://concla.ibge. gov.br/estrutura/natjur-estrutura/natureza-juridica-2016.

44. Brazilian Institute of Statistics and Geography. Regional Division. Accessed 16 Nov 2016. http://www.ibge.gov.br/home/geociencias/geografia/default div_int.shtm?c=1.

Submit your next manuscript to BioMed Central and we will help you at every step:

- We accept pre-submission inquiries

- Our selector tool helps you to find the most relevant journal

- We provide round the clock customer support

- Convenient online submission

- Thorough peer review

- Inclusion in PubMed and all major indexing services

- Maximum visibility for your research

Submit your manuscript at www.biomedcentral.com/submit
Biomed Central 